\title{
NUMERICAL ANALYSIS OF HISTORICAL REINFORCED CONCRETE SHELL
}

\author{
PETR KNĚŽ ${ }^{1 *}$, PETR TEJ $^{1}$ AND JIŘÍ KOLÍSKO \\ ${ }^{1}$ Czech Technical University in Prague, Klokner institute \\ Šolínova 7, 160 00, Prague, Czech Republic \\ e-mail: petr.knez@cvut.cz, www.klok.cvut.cz/en (*corresponding author) \\ \{petr.tej, jiri.kolisko\}@cvut.cz
}

Keywords: Historical Structure, reinforced concrete shell, numerical analysis

\begin{abstract}
This article is focused on the numerical analysis of the historical structure of the reinforced concrete shell. Shells form the roof of the tram depot. It was built in the 50s of the 20 th century. The shells are conoid shaped with a control curve in the form of a catenary. The construction of the depot began to show excessive deformation and lose its stability. At present, the depot is out of service and the shells are temporarily supported. This prompted the commissioning of a diagnostic survey and numerical analysis of the structure. The diagnostic research revealed the quality and strength of the concrete, the reinforcement of the structure, the actual thickness of the shells, the structure of the roof cladding and defects in the structure (cracks, etc.) At the same time, the bottom surface of the whole structure was scanned with a $3 D$ scanner and selected points of the structure were measured by geodetic methods. Numerical analysis focused on one shell at the edge of the depot structure. The model was created in Atena $3 D$ software. The main aim of the analysis was to determine the behavior of the structure under load and to predict the ways of its deformation for different loading methods to determine the possible reason for the current deformed shape. Consequently, compare these predicted behaviors with the real deformed structure, whether its deformation corresponds to normal behavior.
\end{abstract}

\section{INTRODUCTION}

The main object of the tram depot Hloubětín consists of a hall with 5 bays. There are 5 parallel tram tracks in each bay, the total number of tracks is 25 . On these tracks tram cars were shut down and their maintenance and repairs were carried out.

The load bearing structure of the hall, roofing and construction of rail supports were built in the 1950s. The reinforced concrete monolithic structure of the hall is formed in the longitudinal direction by associated frames - columns and longitudinal girders. In the longitudinal direction, the structure is divided into 3 expansion units of 4,5 and 4 frames, ie a total of 13 frame constructions $=13$ fields. The hall of the depot consists of 6 rows of these frames -2 outer and 4 inside, which create just 5 bays of tram depot. In the transverse direction, the longitudinal frames are connected by transverse arched girders with a curved rod. It is a sawtooth arrangement of roofing with vertical girders. The areas between longitudinal and transverse girders are covered with reinforced concrete monolithic shells $18.8 \mathrm{~m}$ wide and $8.75 \mathrm{~m}$ long, 
typically $50 \mathrm{~mm}$ thick - according to project. These are the shells used to roof the depot instead of the originally designed steel roof structure due to lack of steel at the time of construction. The shells have the shape of a conoid with a control curve in the form of a catenary. In total, the hall is covered with $65(5 \times 13)$ shells with total floor plan dimensions $\sim 114.25 \times 94.0 \mathrm{~m}(\mathrm{~L}$ $\mathrm{x}$ W)

Operation of the tram depot Hloubětín was launched on March 10, 1951, all original bays were put into operation at the beginning of 1952.

During the operation of the depot, the insulation of the roof cladding was reconstructed. The original composition of the roof cladding (Heraklit wood fiber insulation + foam concrete with a total thickness of $100 \mathrm{~mm}$ ) was removed. It was replaced by mechanically anchored thermal insulation thickness $\sim 60 \mathrm{~mm}$ (polystyrene or mineral fibers) covered with asphalt insulating strips.

The structure was supported by temporary supports and was in disrepair due to excessive deformation of the shells - locally deviating from the ideal shape up to $150 \mathrm{~mm}$, indicating a loss of stability and a change in the behavior of the structure.
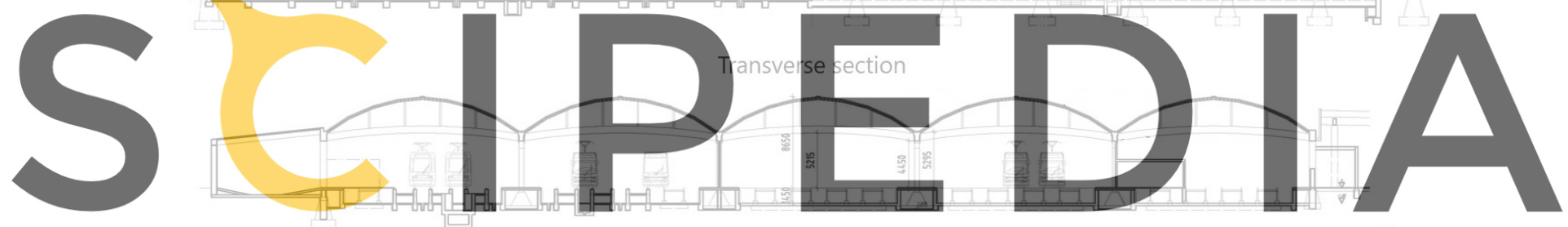

Register for free at https//www.scipedia.comflet download the version without the watermark

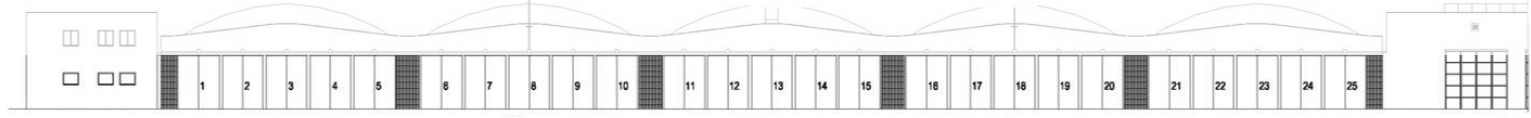

Figure 1: Longitudinal and transverse section and front view of tram depot

The structure was evaluated several times to determine the load-bearing capacity of the structure, but nobody looked in detail at the possible cause of the failure. It has been concluded that the structure does not meet the requirements according to European standards and there is no possibility to improve this situation by possible reinforcement of the structure.

\section{CONCLUSION OF DIAGNOSTIC SURVEY}

A diagnostic survey was carried out on the construction of the depot. It was focused on finding the material properties of the elements of the load bearing structure - girders, columns and shells. Another important part of the survey was to determine the real reinforcement of shells using destructive and non-destructive methods. Part of the survey was also localization 
of detected failures - cracks in concrete, reinforcement corrosion, excessive deformations, etc. The survey was completed with a 3D scan of the bottom surface of all 65 shells.

The diagnostics showed:

- In most cases, the shells exhibit a visually apparent typical deformation manifested by symmetrically placed two 'bent down'.

- Cracks signaling tensile stress were diagnosed at the point of additional support of the shells.

The shells show obvious deformations (Figure 2, 3) and their center line deviates significantly from the ideal shape of the shells from the project. This shape fundamentally affects the unsatisfactory static behavior.

The following facts were recommended for nonlinear calculations:

- $\quad$ Strength of concrete C25/30.

- The reinforcement of the shells is in good agreement with the original project and consists of smooth rods with a diameter of $5.5 \mathrm{~mm}$.

- The recommended design yield strength of the reinforcement is $180 \mathrm{MPa}$.

- The coverage of the reinforcement when measured from the lower face is very variable and oscillates over a wide range of 5-25 mm.

The thickness of the shells is also highly variable and oscillates in the range of 35-65 $\mathrm{mm}$.

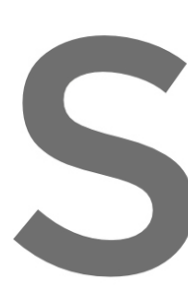

The roof cladding

insulation, which is mad

made of EPS (expandec
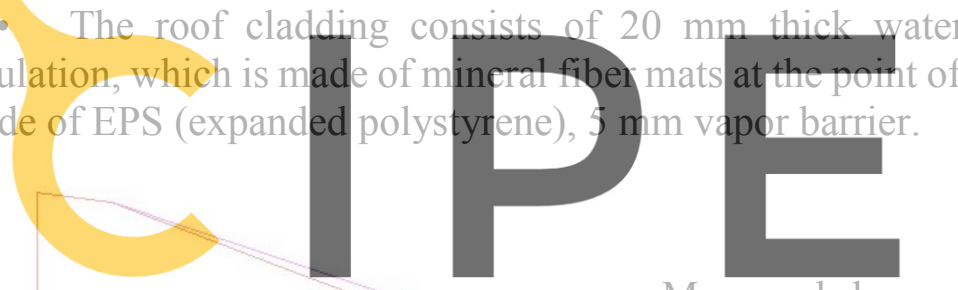

Measured shape of shell

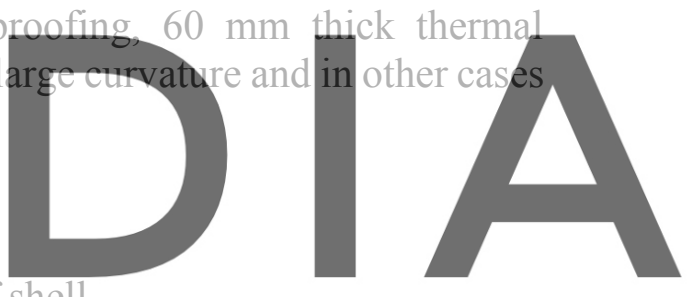

Register for free at https//www.scipedia.com to download the version without the watermark

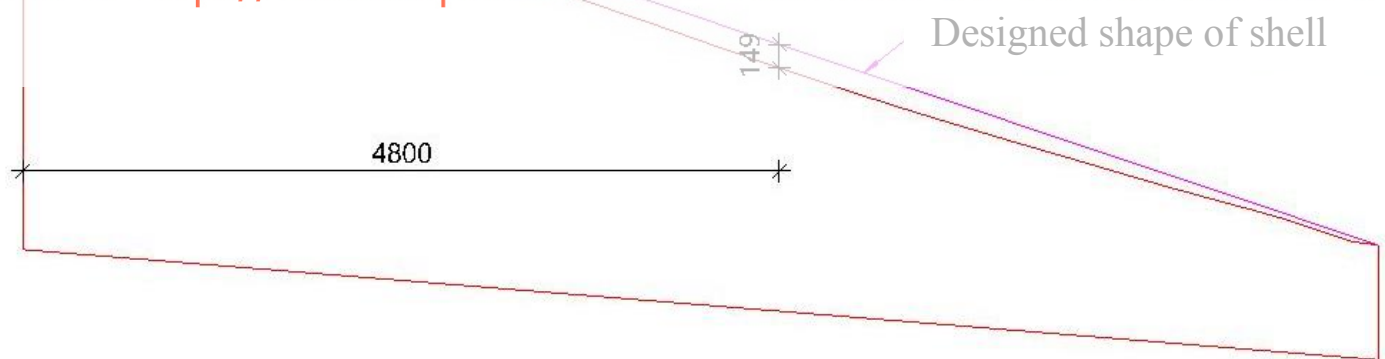

Figure 2: Longitudinal section of the shell at the point of greatest deformation, added shape according to the design 


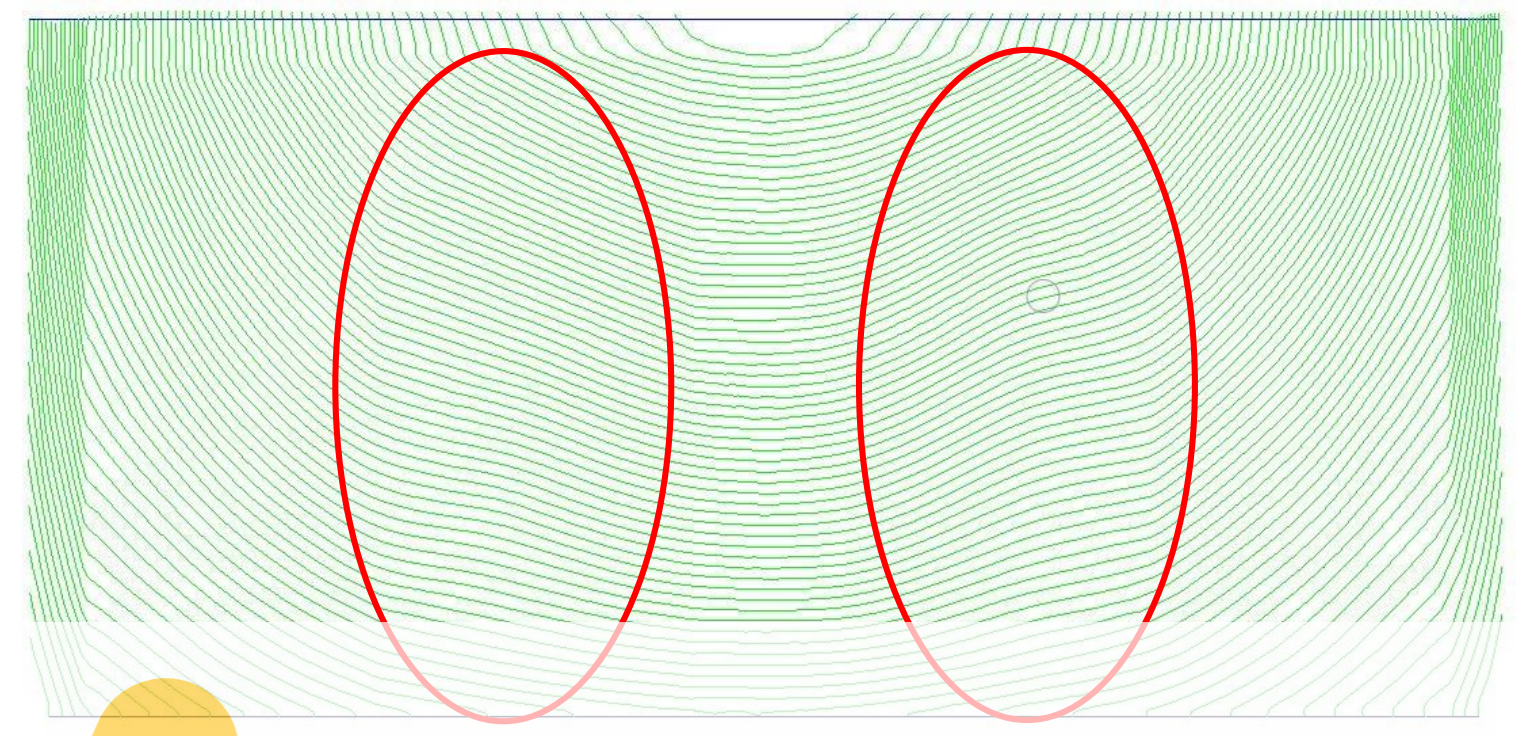

Figure 3: Contour line after scanning the bottom surface of shell shell 7 in field 5 - plan view. Areas with pronounced bulges marked.

NUMERICAL ANALYSIS - MODELS

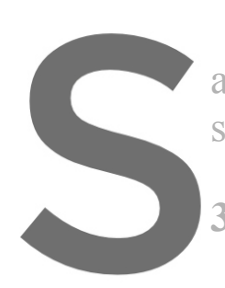

The numerical anat

and also on the model,

shell lying in the center

3.1 Numerical model of i

Based on the preserved fragments of the or
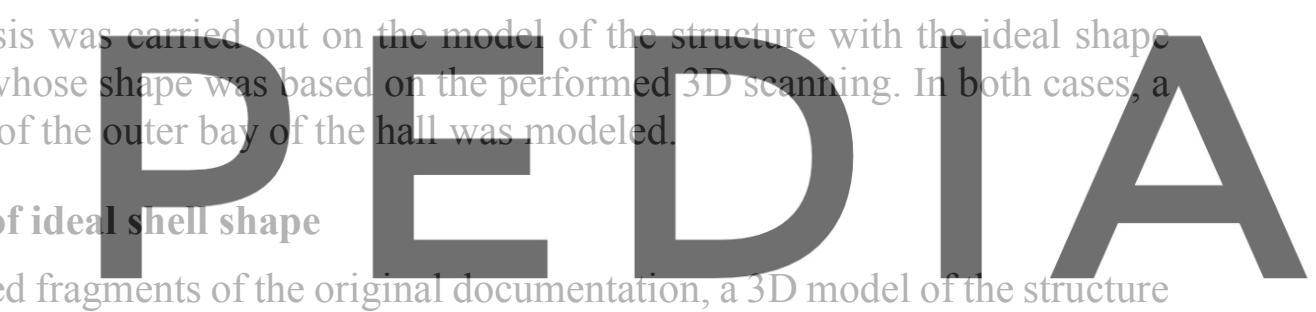

has been worked out, on the basis of which the computational model of the structure was created

Register fpr $r_{\text {thee }}$ at httpsldansww.scipedia.com to download the version without the watermark

The model captures one shell, located in the center of the outer bay of the hall. Thus, the

caiculated structure is prevented in three directions from shifting by the "rest" of the structure and one side may deform. This arrangement is a simplification of the complex relationships that influence the individual elements of the roofing - ideally, it would be possible to have a model of the entire expansion unit, which, given the dimensions of the structure, could not be managed with commonly available computer equipment. The individual shells and the supporting elements interact with each other - bringing additional loads and forced displacements for the part of the structure considered by us that are not taken into account.

The shell is modeled with the thickness by the project - it is $50 \mathrm{~mm}$, which is measured vertically. The shell is double curved, so it is divided into a series of smaller elements to make the mesh element generator able to work with these elements. As a result, the model with the ideal shell shape consists of 320 macroelements (Figure 4). 


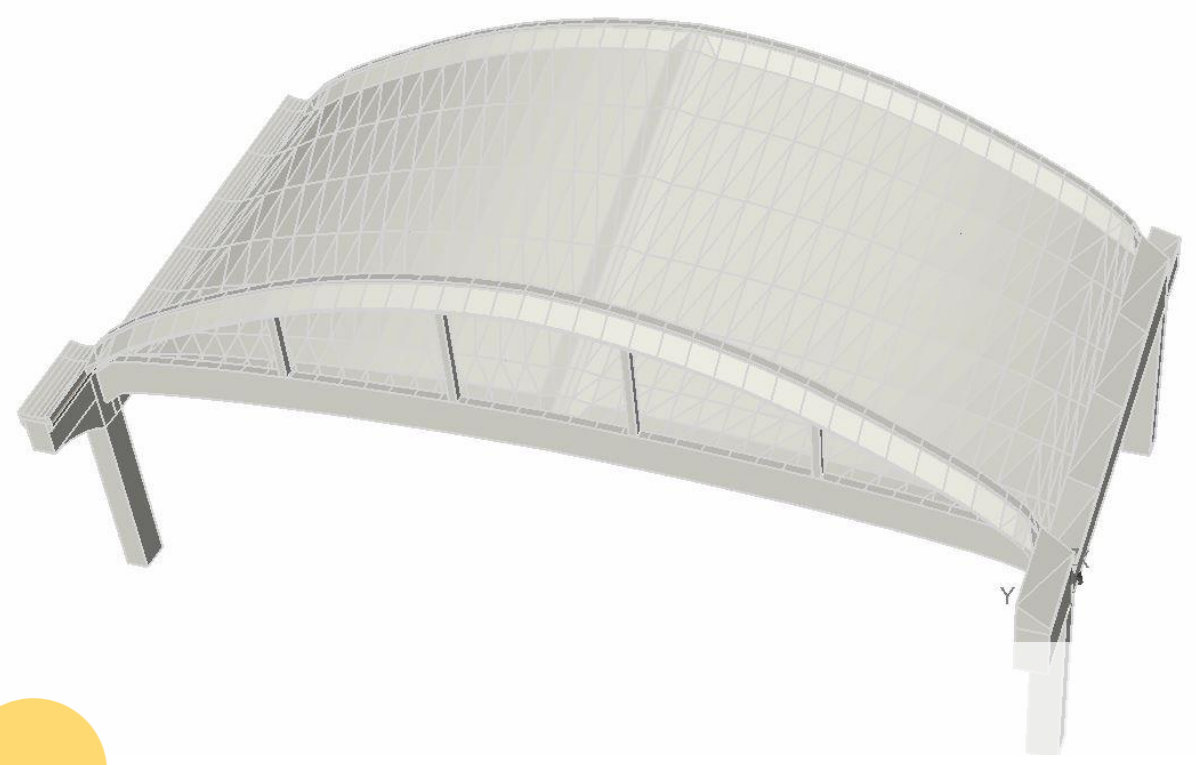

Figure 4: Model of ideal shell shape

The model is reinforced according to the drawings of the preserved historical documentation. All members are inserted into the model as discrete models (= each member is physically modeled and can show stress). The shell is reinforced with $8 \varnothing 5.5$ per meter in both directions and the upper reinforcement is added at the point of attachment. Reinforcing diameters 14,16 and 20 5 and $7 \mathrm{~mm}$ for stirrups ate The model contains 2033 bar reinforcements (Figure 5).

The model consist of a finite element mesh

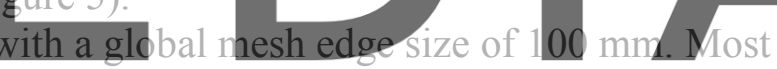

of the macroelements are meshed by tetra elements. The model consists of 307623 finite

Register folprfreeds a a

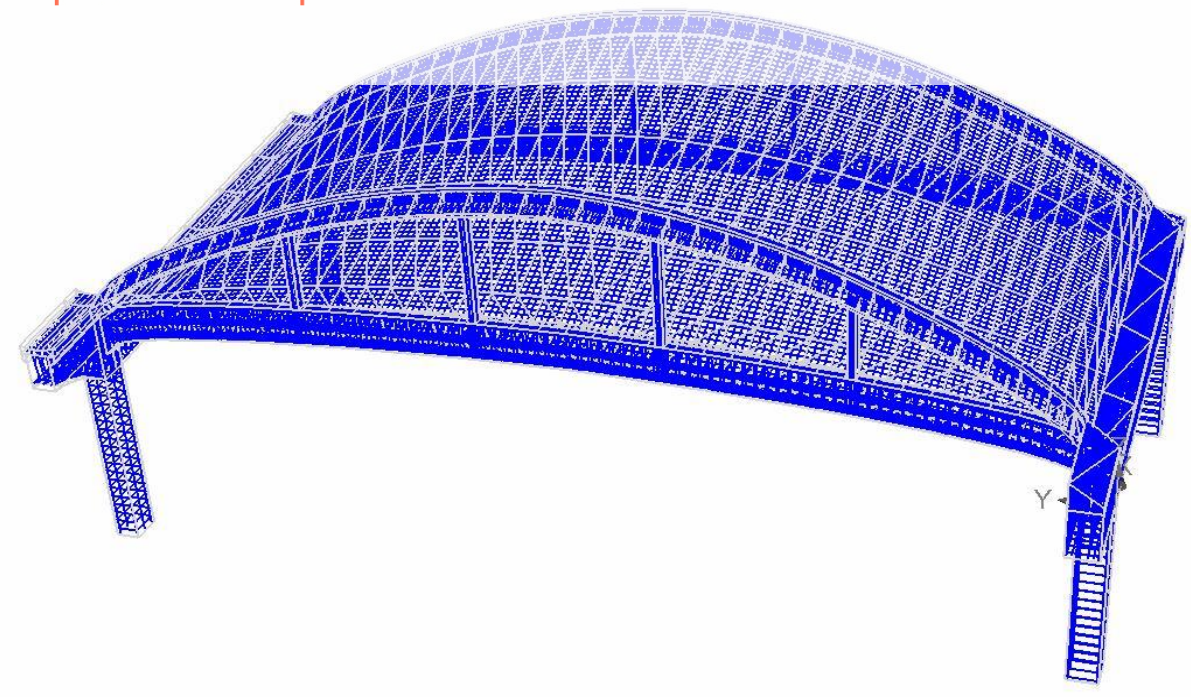

Figure 5: Model with reinforcement 

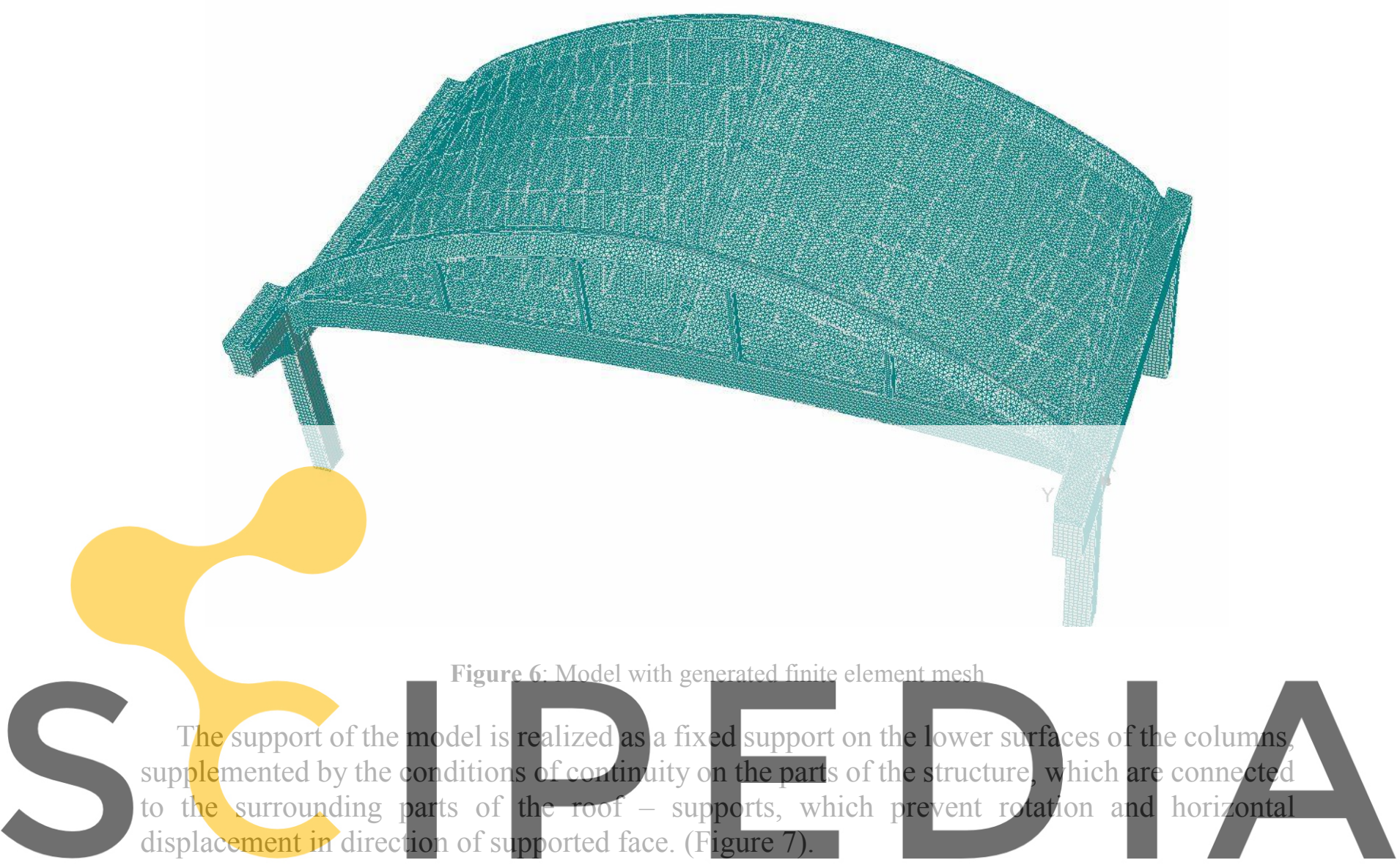

Register for free at https//www.scipedia.com to download the version without the watermark

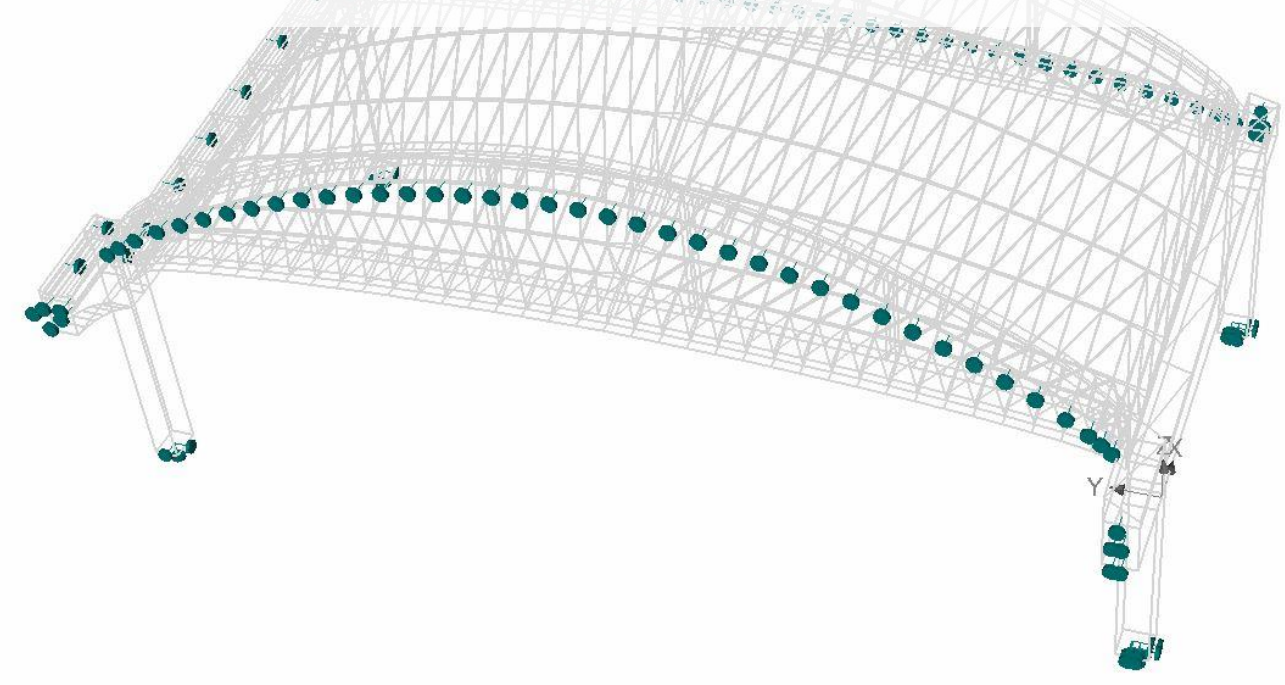

Figure 7: Model with applied supports 
The structure is loaded by its own weight, load from the roof cladding, snow (even and windblown) and temperature $\left( \pm 20^{\circ} \mathrm{C}\right)$.

\subsection{Numerical model of actual shell shape}

Based on the measurement of the actual shell shape using a 3D scanner, the shell model was created in Atena 3D. It is a shell placed in the same part of the depot as a model of ideal shell shape. The support elements of the shell are again modeled on the basis of preserved documentation.

Since the already deformed structure is modeled, it is not possible to re-load it with dead loads (self-weight and other dead loads) as they would generate additional deformations that are already part of the model. However, these loads on the structure create some unknown stress state, which has a major impact on results. We tried to take this into account by reducing some of the material properties based on the results on an ideal shape model. Cracks on the actual structure were also detected by diagnostics, which is another parameter that is very difficult to take into account when modeling the structure. However, these cracks affect the rigidity of the structure. Due to the orientation of the cracks, their cause is not most likely to be caused by force loads, but cracks caused by non-force effects (temperature, drop in supports).

The shell is modeled with an average thickness according to the survey - it is $48 \mathrm{~mm}$, which is measured vertically. Shell elements were divided according to the needs of the program into smaller partial parts (shell on parts approx. 0.4x0.4 $\mathrm{m}$ - for the possibility of capturing

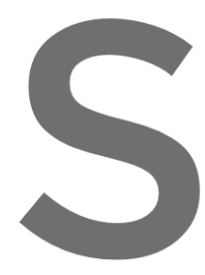
deformations), some consists of a total of 211
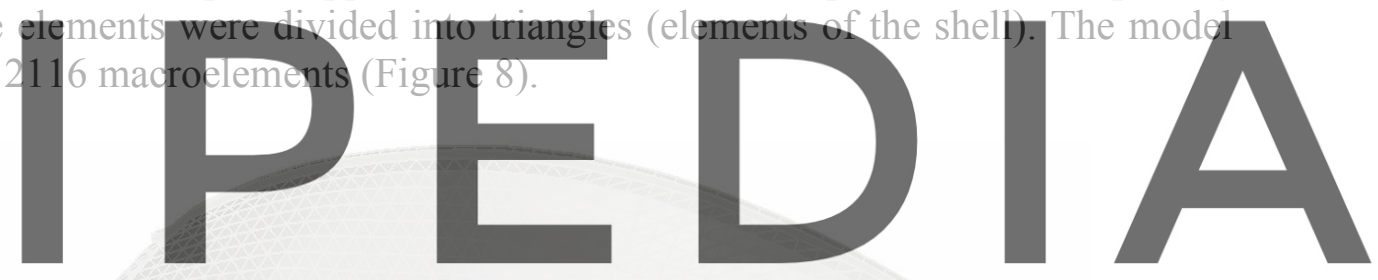

Register for free at https//www.scipedia.com to download the version without the watermark

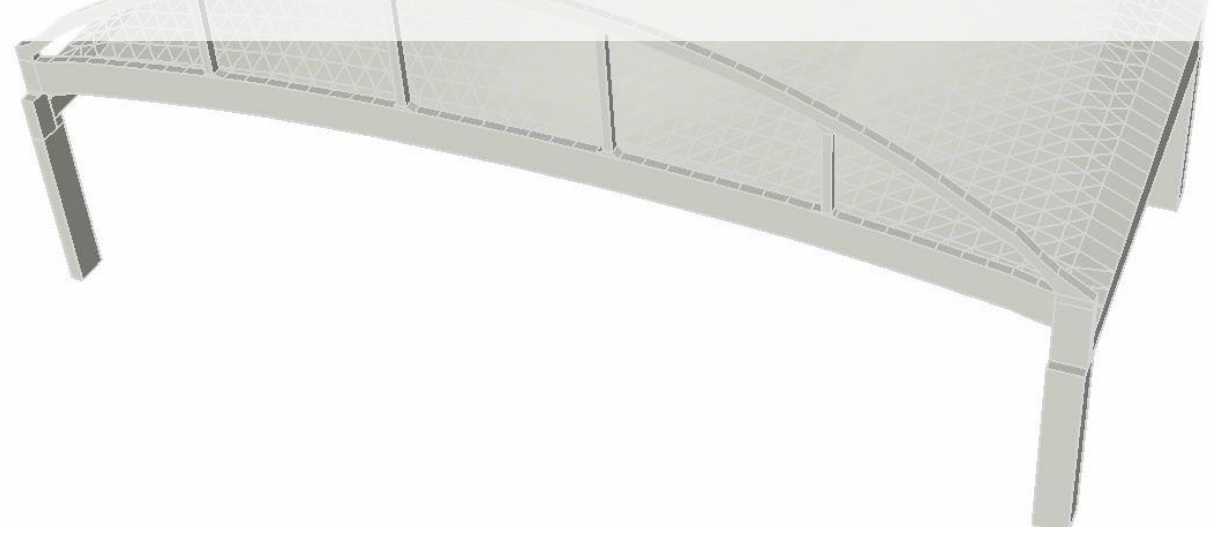

Figure 8: Model of actual shell shape

The reinforcement of the model is almost the same as the model with the ideal shape. The difference is due only to the unsymetry of the structure. The reinforcement bars of the shell follow the deformed shape. Reinforcement of beams is simplified - instead of bent 
reinforcement, straight profiles are used to match the number of reinforcement bars in critical sections. The model contains 974 bar reinforcements (Figure 9).

The finite element mesh is generated according to the same principles as described for the ideal shape model. The model consists of 277613 finite elements in total. Model supports, snow and temperature loads are also the same (Figure 10).

Only dead loads are not considered, as explained in the introduction to this chapter.

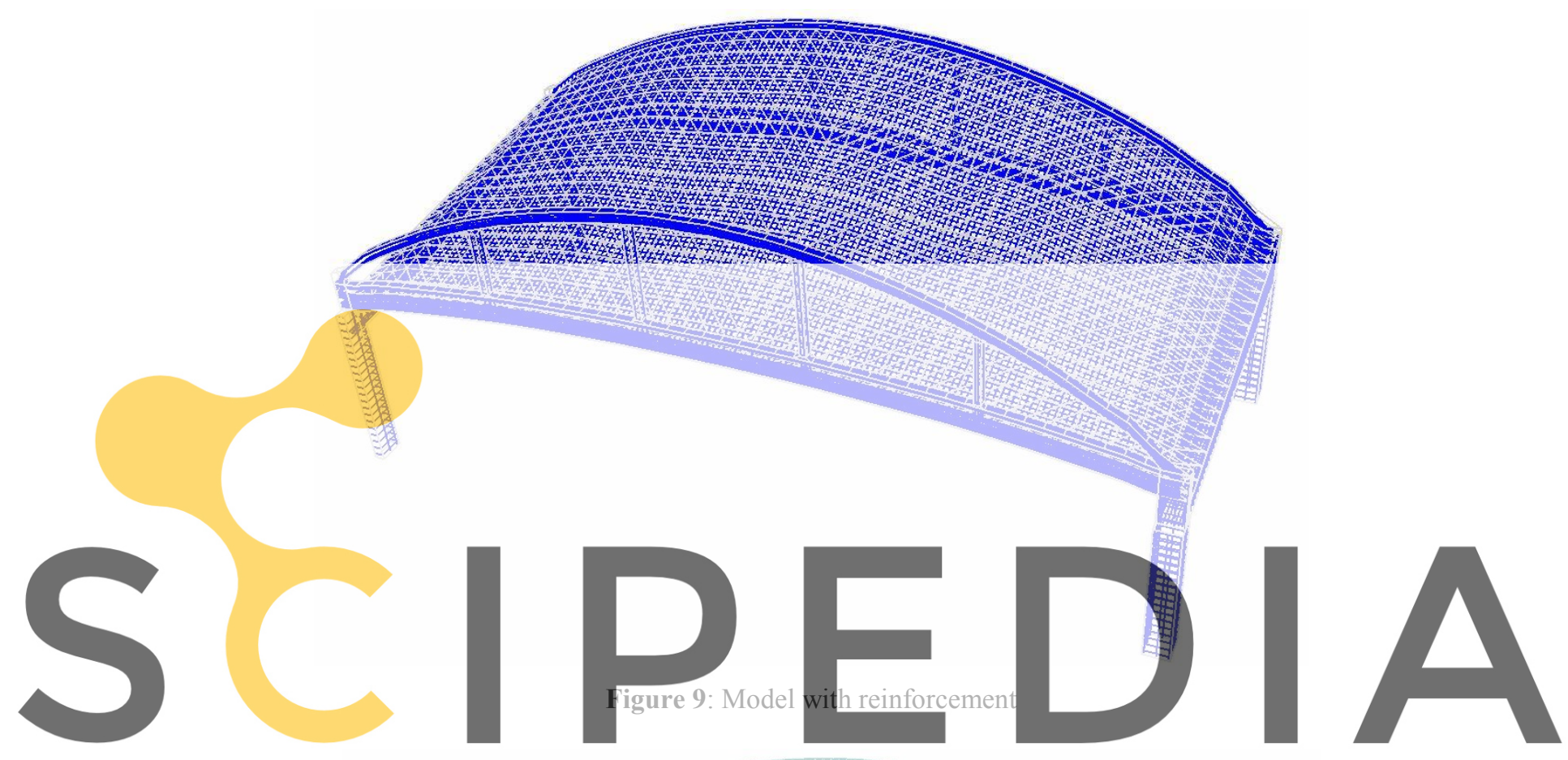

Register for free at https//www.scipedia.com to download the version without the watermark

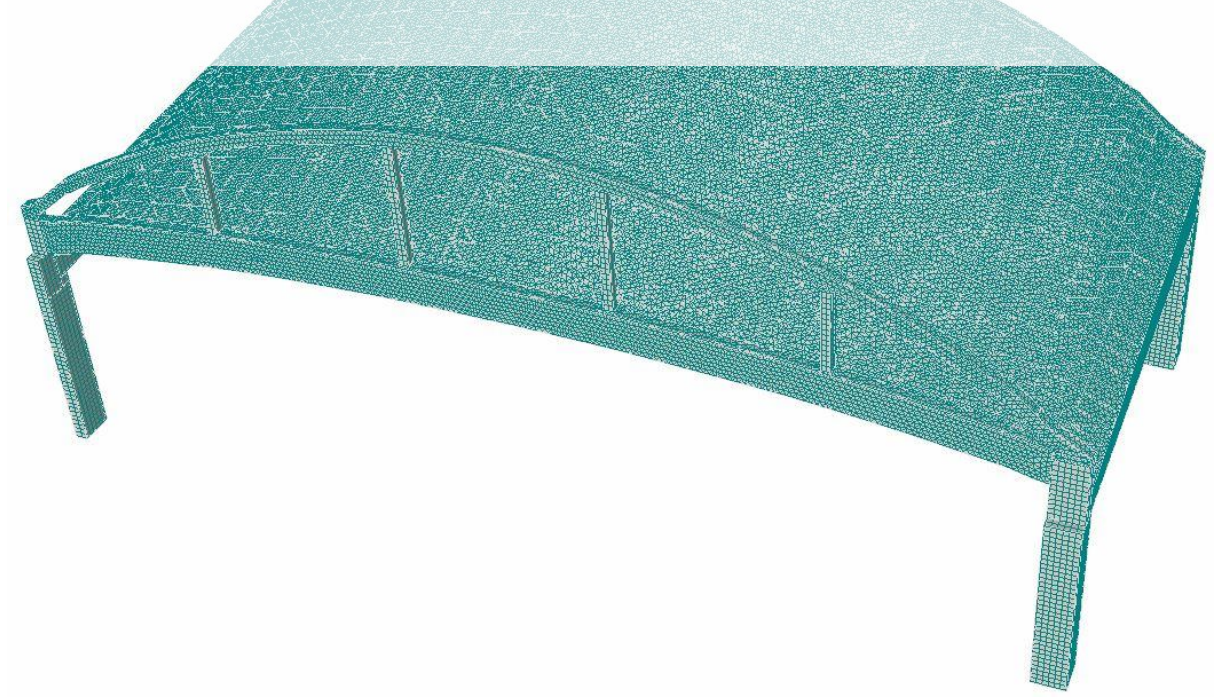

Figure 10: Model with generated finite element mesh 


\subsection{Materials}

The proposed material strengths are not available in the original documentation, so the concrete strengths found in our diagnostic survey are used and the material characteristics of the reinforcement are determined on the basis of tests performed on the cut-outs.

Laboratory tests on concrete samples result in the use of concrete strength class C25/30. Used material model works with mean values of strength and basic values are given in Table 1 . This material model is used for the whole model of the ideal shell shape and for the beam elements of the actual shell shape model. The material model used on the model of the actual shell shape is divided into two categories. The first is applied to the most parts of the shell and simulates the initial stress state (Table 2). The second category material model is used in place of cracks found by survey (Table 3 ).

The material model 3D nonlinear cementitious $2[1,2,7]$ was used for the numerical analysis. It takes into account the plastic deformation of concrete and its tensile softening after the crack.

Table 1: Mateial characteristics of concrete class C25/30 Mean

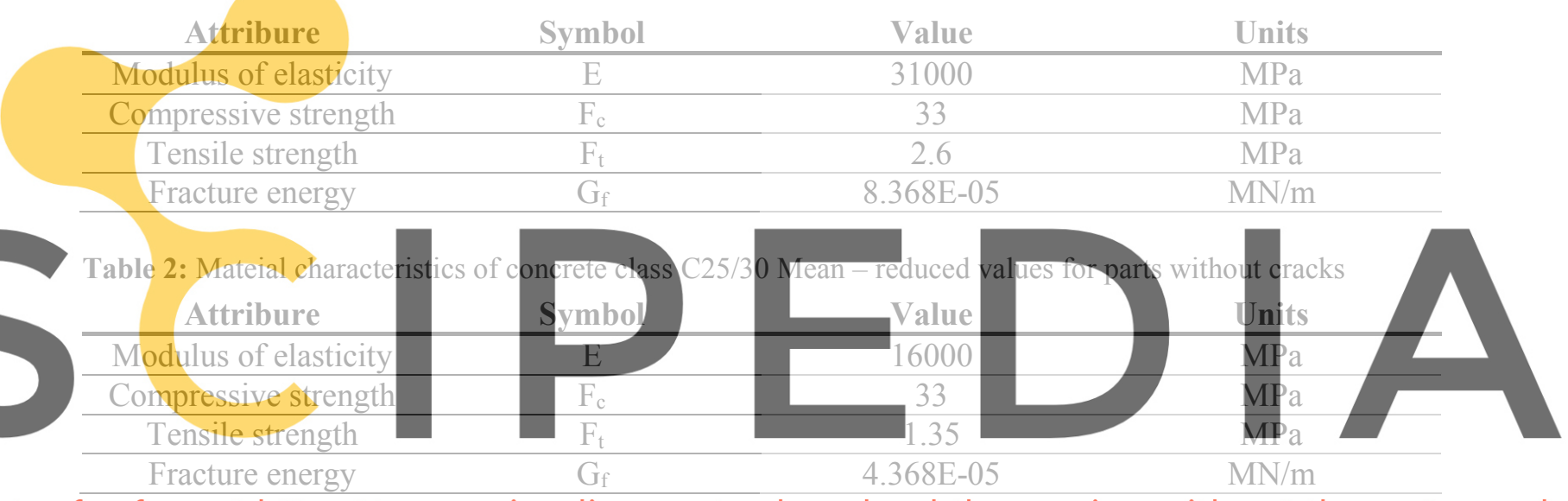

Register for free at https//www.scipedia.com to download the version without the watermark Table 3: Mateial characteristics of concrete class C25/30 Mean - reduced values for parts with cracks

\begin{tabular}{cccc} 
Attribure & Symbol & Value & Units \\
\hline Modulus of elasticity & $\mathrm{E}$ & 16000 & $\mathrm{MPa}$ \\
\hline Compressive strength & $\mathrm{F}_{\mathrm{c}}$ & 33 & $\mathrm{MPa}$ \\
\hline Tensile strength & $\mathrm{F}_{\mathrm{t}}$ & 0.5 & $\mathrm{MPa}$ \\
\hline Fracture energy & $\mathrm{G}_{\mathrm{f}}$ & $8.368 \mathrm{E}-06$ & $\mathrm{MN} / \mathrm{m}$ \\
\hline
\end{tabular}

The reinforcement for model of ideal shell shape is modeled using a bilinear material model with hardening with a yield strength of $280 \mathrm{MPa}$, an ultimate strength of $400 \mathrm{MPa}$ and a maximum elongation of $10 \%$. The reinforcement for model of actual shell shape is modeled using a bilinear material model with hardening with a yield strength of $170 \mathrm{MPa}$, an ultimate strength of $250 \mathrm{MPa}$ and a maximum elongation of $7 \%$ due to initial stress state. 


\section{NUMERICAL ANALYSIS - RESULTS}

\subsection{Results for model of ideal shell shape}

Calculations have shown that the weak points are in particular the supporting structures, namely the arc tie rod, frame joints and column (Figure 11, 12). The design is strongly influenced by volume changes due to temperature load. The dilatation units are relatively large and the deformations add up. Cooling of the structure results in tensile stress of the elements (a possible source of cracks for both the shell and the beam members), warming then stresses the structure by pressure (potentially there is a loss of stability and buckling of thin-walled elements)

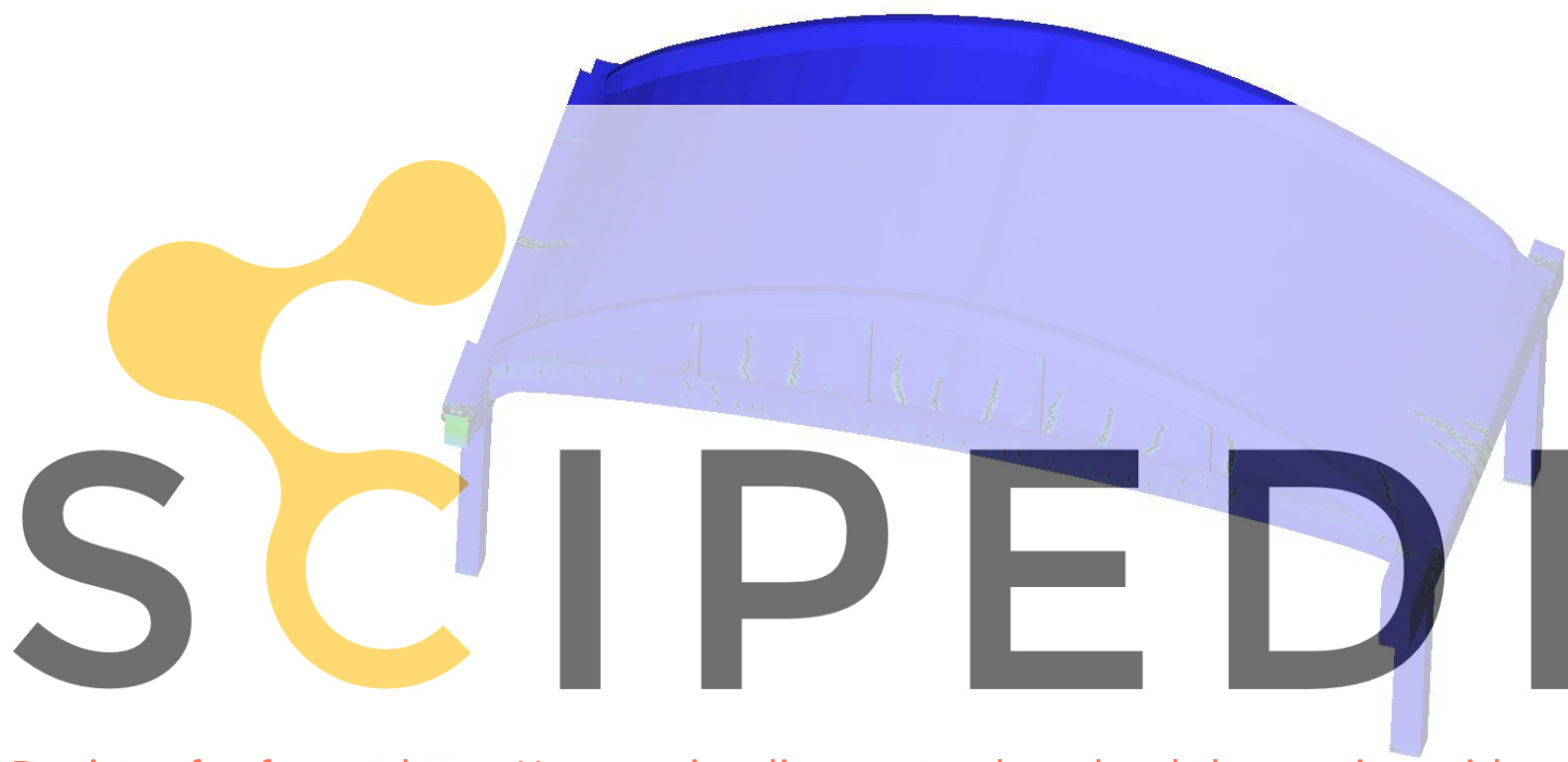

Register for free at https//www.scipedia. com to down.load the version without the watermark

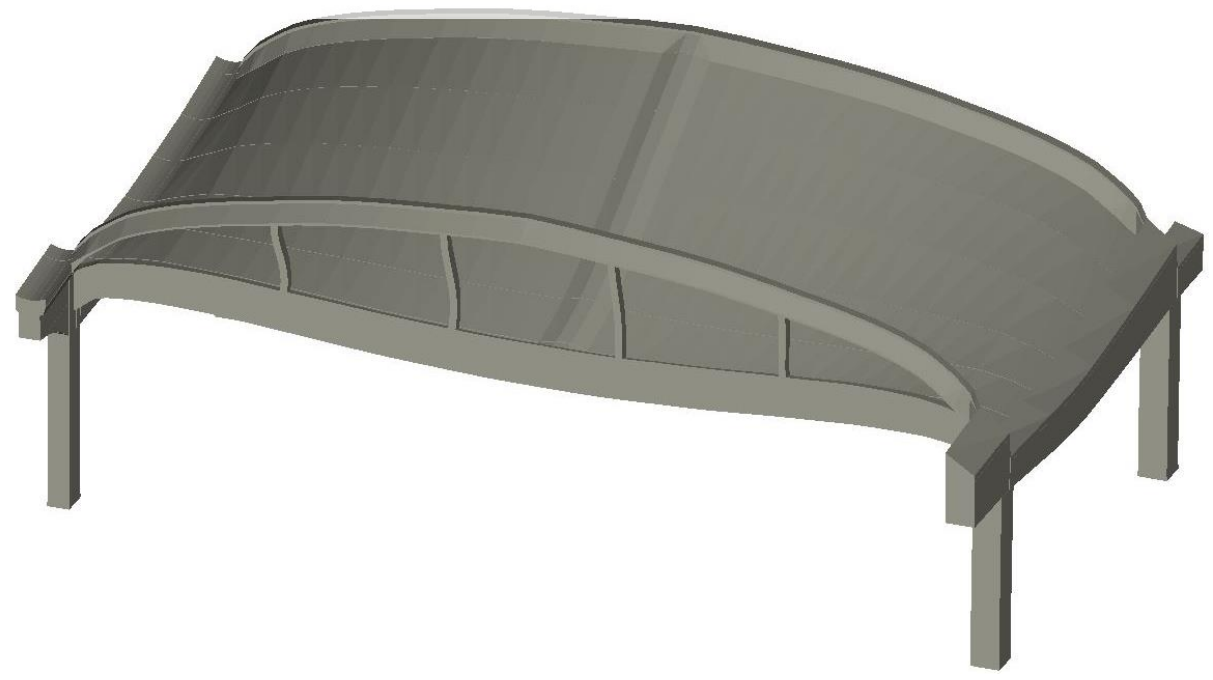

Figure 12: Deformed model of ideal shell shape, deformation scale 100:1 


\subsection{Results for model of actual shell shape}

The results are based on the assumptions outlined above and are of an informative nature and very approximate. Generally, it can be stated that tensile stresses occur at the structure at the point of "bulges" and continue to contribute to the deterioration of the current state (Figure 13). According to the survey, deformations of up to $150 \mathrm{~mm}$ occur on the structure, a value that indicates a serious problem.

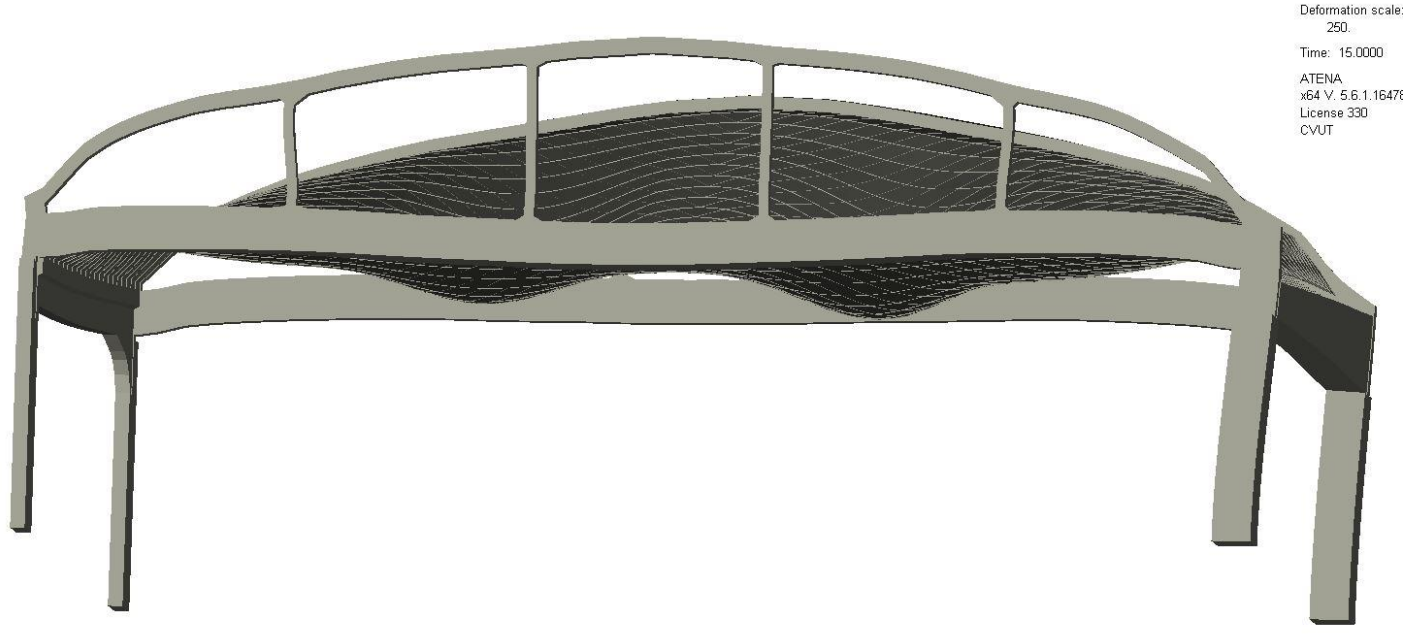

Figure 13: Deformed model of actual shell shape, deformation scale 250:1

\section{CONCLUSION}

The vast majority of shells typically have a deformed shape formed by two bulges (see Figure 13). The absolute size of the bulges varies from shell to shell. According to the survey, deformations of up to $150 \mathrm{~mm}$ occur on the structure, a value that indicates a serious problem.

The assessment of the shell structure in the ideal shape according to the archival documentation did not prove a possible cause of the actual deformations found by the survey. The existing deformed shape of the shells determined by the measurements does not correspond to the deformations resulting from the analysis of the structure (Figure 12). Both in shape and in absolute values of deformation, taking into account creep over time. The shell was loaded with positive and negative temperature, blown snow and local loads possible during the maintenance of the roof in accordance with European standards.

This analysis confirmed only the frequent phenomenon when historic reinforced concrete structures are not sufficiently reinforced when assessed according to current standards. The volume of reinforcement would be sufficient, but due to its lower strength, the result is an unsatisfactory assessment of the ultimate limit state.

The reason for the current atypical deformation of the shells is thus not entirely clear. It is not possible to exclude initial imperfections from the time of construction, which were gradually enhanced by the creep of structures. Alternatively, there could also be local overloading of the shells, eg during the replacement of the roof cladding in 1994. However, damage to the structure during the replacement of the roof cladding seems to be the most likely reason that triggered the degradation of the shells. The original construction of the foam concrete roof cladding would have to be removed very gently, which probably did not happen, 
moreover, it was not necessary from a static point of view. The subsequent new roof cladding formed by thermal insulation was mechanically anchored directly into the shell structure, where these anchors pass in a number of places completely through the entire thickness of the shell and are visible from the interior.

However, the final evaluation of the current state of the structure is unchanged regardless of the cause of its origin. There are tensile stresses on the structure at the location of the "bulges", which are unacceptable for this type of structure. The current irregularly deformed shape in combination with an improperly designed support (low stiffness) substantially contributes to a further gradual deterioration of the shells and ultimately their unpredictable behavior.

\section{Acknowledgements.}

This project was supported by a grant from the Ministry of Culture of the Czech Republic NAKI II DG20P02OVV005 and a CTU student grant SGS19/138/OHK1/2T/31.

\section{REFERENCES}

[1] Červenka, J. and Papanikolaou, V.K. Three dimensional combined fracture-plastic material model for concrete. Int. journal of plasticity, 2008

[2] Červenka, V., Červenka ,J.and Pukl, R. ATENA - a tool for engeneering analysis of fracture in concrete. Sadhana, 2002

[3] Model Code for Concree Structures 2010, Fib, Ernst \& Sohn, 2013

[4] Czech standard ČSN EN 1992, Design of concrete structures. Czech Standards Institute, 2011

[5] Czech standard ČSN EN 1991, Actions on structures. Czech Standards Institute, 2011

[6] Kněž, P., Štemberk, P., Tej, P. and Kolísko, J. Expert Report, evaluation of the static reliability of shells of the roof construction of the tram depot based on a survey and static non-linear analysis. Klokner institute, 2019

[7] Červenka, V., Jendele, L. and Červenka, J. Atena program documentation, Part 1 - Theory. Cervenka Consulting, 2018 